\section{Las diferencias socioeconómicas y las tasas de cesáreas en los países en desarrollo}

La relación entre las inequidades socioeconómicas y el uso de los servicios de salud materno-infantil ha atraído la atención de los profesionales de la salud pública y las autoridades nacionales de salud en los últimos años. Con frecuencia, las diferencias en el acceso a la salud materna son más pronunciadas entre los distintos grupos socioeconómicos de un país que entre países con diferentes niveles de desarrollo, y mayores que las diferencias observadas en el acceso a la atención de salud infantil.

Sin embargo, a pesar de que el acceso de las mujeres a una atención hospitalaria competente resulta esencial para reducir los niveles de mortalidad infantil, poco se conoce acerca de los factores socioeconómicos que influyen en su acceso a la atención obstétrica especializada basada en hospitales.

En este trabajo se analizan las diferencias en las tasas de cesáreas según los grupos socioeconómicos de diversos países en desarrollo. Para ello se utilizaron los datos de 199916 partos exitosos de 42 países, de ellos 26 de África subsahariana, 7 del sur y sudeste de Asia y 9 de América Latina y el Caribe (Bolivia, Brasil, Colombia, Guatemala, Haití, Paraguay, Perú, Nicaragua y República Dominicana). En todos los casos se contó con la información de las cesáreas practicadas y del nivel socioeconómico de la familia a partir de las encuestas nacionales de demografía y salud más recientes. Los países seleccionados constituían aproximadamente 59\% de todos los nacimientos vivos de los países en desarrollo en el año 2000.

Los resultados demostraron que el grado de acceso a las cesáreas varió considerablemente tanto dentro de los países como entre ellos. En un extremo se situaron los países más pobres, la mayoría de África subsahariana, donde una gran parte de la población tiene poco acceso a los servicios especializados, independientemente de su nivel socioeconómico. En el otro extremo se encuentran siete países, la mayoría de América Latina, en los que la tasa de cesáreas es excesiva en al menos $40 \%$ de la población.

La elevada y creciente tasa de cesáreas en América Latina ha sido bien documentada, incluso en países de ingresos medios como los que formaron parte de esta muestra. A pesar de que los productos internos brutos de Nicaragua y Bolivia son mucho menores (entre la mitad y la cuarta parte) que los de los otros países de este grupo, las tasas de cesáreas en el grupo de mujeres de mayor nivel socioeconómico de esos países fueron de $35 \%$ y $44 \%$, respectivamente, en comparación con las tasas respectivas de 3\% y $4 \%$ observadas en los grupos socioeconómicos más pobres. Otros países con tasas excesivas de cesáreas en los grupos de mayor nivel socioeconómico fueron Sudáfrica $(30 \%)$, Vietnam (26\%), Filipinas (20\%) e India (20\%). Las razones de estas elevadas tasas de cesáreas son diversas, entre ellas, las decisiones personales sin justificación médica, ya sea por los incentivos financieros, el temor a las demandas por negligencias, la conveniencia de los médicos o las preferencias de las pacientes embarazadas. La elevada tasa de cesáreas $(77 \%)$ en el $10 \%$ de mujeres de mayor nivel socioeconómico de Brasil confirma que las cesáreas se han convertido en la norma para algunas mujeres. Las intervenciones realizadas para reducir esta tendencia creciente de cesáreas innecesarias no han dado los resultados esperados, por lo que se deben buscar nuevas vías que permitan evitar el abuso de esta práctica potencialmente peligrosa y muy costosa.

Dado el papel que pueden desempeñar las cesáreas en la atención obstétrica de emergencia y las inequidades que resultan enmascaradas por las tasas nacionales de cesáreas, se recomienda utilizar esta tasa como un indicador complementario de las tasas de atención médica especializada. Las inequidades presentadas en este trabajo reflejan la desigualdad en el acceso a la atención médica especializada y merecen la atención inmediata de las autoridades sanitarias nacionales e internacionales. (Ronsmans C, Holtz S, Stanton C. Socioeconomic differentials in caesarean rates in developing countries: a retrospective analysis. Lancet. 2006;368: 1516-23.)

\section{Influenza aviar: aprendiendo de la experiencia de Vietnam}

A pesar de los millones de casos documentados de influenza aviar y de la identificación de más de 200 personas infectadas, aún no se conoce lo suficiente sobre esta infección, especialmente en regiones como las Américas, en las que aún no se ha propagado ampliamente. Por ello es importante conocer mejor la experiencia acumulada en otros países que han enfrentado con relativo éxito esta grave epidemia, como Vietnam.

En este trabajo se analizan documentadamente las fuentes de infección y las posibles vías de transmisión a personas, sobre la base de la experiencia acumulada y los resultados de un estudio de casos y controles de personas infectadas con el virus de la influenza aviar A H5N1 (influenza H5N1) en ese país del sudeste asiático.

Se estudiaron 28 casos confirmados de influenza H5N1 procedentes de 15 provincias de Vietnam; de ellos $21(75 \%)$ fallecieron de esa enfermedad. La confirmación se realizó mediante transcripción inversa y reacción en cadena de la polimerasa. El diagnóstico de influenza H5N1 se confirmó mediante pruebas de laboratorio en 25 casos y en 12 se logró aislar el virus H5N1. 